\title{
The Phenomenon of Musical Art in the Education of Individuals
}

\author{
Jerdimaliyeva Ritta ${ }^{1}$, Abeltayeva Janel${ }^{1}$, Elubaeva Marjan ${ }^{1}$, Akhmetbekova Dauresh ${ }^{2}$, \\ Imasheva Aigul ${ }^{2}$ and Kusametova Gulsum ${ }^{3}$
}

${ }^{1}$ Kazakh National Academy of Arts T. Zhurgenov, Kazakhstan

${ }^{2}$ Kazakh National Conservatory Kurmangazy, Kazakhstan

${ }^{3}$ Aktobe Regional University K. Zhubanov, Kazakhstan

\begin{abstract}
Phenomenon of musical art considered as one of the conditions needed to create artistic and aesthetic communication that nurtures the growth of a spiritual, moral and harmonious personality. This article focusses on finding new bases for music education. It outlines current music education and points out difficulties that are caused by rapid changes in music culture. Due to these changes, music curriculum must find new starting points. We explored and compared the main ideas about music education in its historical development. We conclude that music education today should be built on music making and listening. It can no longer be based on traditional frameworks because they are not familiar to individuals today. Music education should be based on research, and new ways of teaching and learning musical skills and knowledge should guide its practice.
\end{abstract}

Keywords: Art of music, education, personality, artistic culture, emotion, ideology, spirituality.

The definition of education has often been based on the idea that it is target-orientated achievement that aims to effect changes in the individual who is being educated. The achieved changes are usually based on musical experience and they should be relatively permanent changes in its behavior. It is also commonly believed that these changes may occur in so-called potential that shapes behavior such as knowledge, skills and emotional reactions that may begin to take effect immediately or later as changed behaviour. Researcher attached to these examples of potential sources of change an adequate educational system as provided for in Western democracies: music education should help pupils to find their own values and course of action, to reach independence and freedom as individuals. This point of view is reflected especially in the underlining of individuality [1].

No one has, so far, been able to develop a general, widely accepted, consistent theory of music education, although some steps have been taken by exploring the joint effect of different theories of teaching, learning and motivation together with orientation [2].

In music education, the starting point has been music itself and its significance and meaning to human beings. These concepts naturally five rise to several basic questions: What is music education, and what should the relationship between music education and

Address correspondence to this article at the Kazakh State National University of al-Farabi, Almaty, Kazakhstan; Tel: +77073851878;

E-mail: zhanat_2006@mail.ru general education be? In the public debate on music education, everyone seems to have an opinion. Some have a positive and others a negative point of view, depending on their own experience in school regarding music lessons, their concept of music or perhaps their experience of music as a hobby outside school. It is reasonable to ask if these perceptions should determine the aims of music education.

The aim of this research is to enhance the methodology of musical art in education.

Undoubtedly, observing music education in schools today will offer more or less adequate information of what music education is at present; this information could be used when music education is developed for future use. The usefulness of music education has also been explored in recent decades and the results have been different, depending on the point of view of the researcher. Speculation on the genuine essence of music education leads us, in any case, to the deepest levels of human consciousness: knowing, feeling, understanding significances and meanings, thinking, learning and teaching, acting and believing. All this takes place in effective music education. It is easy to see that music education is closely connected to human life at the individual level and public cultural level as well as to the professional level of music teachers and students. Thus, music education collects significant and substantial meaning as part of general educational achievement. The deepest essence of music education always directly affects human achievement and everyday life. 


\section{METHODS}

Survey method was used in the study. The subjects were administered a questionnaire in which they were asked to answer questions related to their profession. Items used in the questionnaire were prepared according to the related literature and interview results conducted with some teachers. Descriptive and inferential analyses were conducted to get a deeper insight into the research questions. Time limit was 90 minutes for the survey.

This qualitative study, carried out by four music educators (teacher educators/authors) in two universities, was based on the constructive approach. Teachers used questionnaires during the study. It supports the student teachers' processes that enable them to teach music in comprehensive schools. The focus was on exploiting students' guided autonomous and contact learning hours while examining the demands of music as a school subject. The paper describes the teacher educators' previous experiences and the research based on their observations, reflections and various data collected from music studies in the class-teacher education context. The constructive approach models a fresh, innovative way to guide student teachers and support their music education path [3].

\section{RESULTS}

The problem of personality has always been and continues to attract increased interest from scientists who are representatives of various fields of scientific knowledge about the nature of man and the nature of his relationship with the surrounding reality. Modern research increasingly tends to reveal the diverse aspects associated with the study of a wide range of manifestations of the personal in society, as evidenced by the words of the famous scientist-psychologist, Ananieva B. G., "Humanity is the main centre of scientific development of modern science". It is not by chance that the views of philosophers-thinkers such as Aristotle and Hegel regarding the cognitive power of musical art in its purposeful influence on the spiritual and moral aspects of the personality never lost their relevance to this day [4].

According to R. Linton, interaction with "an open culture" and the experience derived from that interaction brings forth a "hidden culture" in the individual based on his or her "psychological state". It is the history of the inner formation of the individual in a concrete historical period that is at the same time a reflection of the individual's social and cultural activity in everyday life that consists of a multitude of diverse experiences, among which music plays an important role. In this context, signs of an emotionally-conscious attitude toward any particular musical culture are perceived only as the result of the dynamics of one's own development and life direction measured by one's reactions to the external environment. Due to the individual's personal, internalised worldview, personal development becomes a sort of indicator of the qualitative transformation taking place in the individual.

Let us recall in this connection that a musical environment can exert a powerful influence on individual-practical experience in the formation of a scale of spiritual values in the aesthetic consciousness of the subject, and this largely determines the level of his artistic needs, inclinations and preferences, among others. The methodological basis for understanding the essential and functional aspects of any kind of art is characterised by a multivariate, the presence of different interpretations regarding the uniqueness of this phenomenon. Thus, among the influential approaches to the evaluation of artistic phenomena, cultural cultivation, laid down in works on philosophy and aesthetics, emphasises the importance of individualised manifestations in the creative interaction of man with art [5].

The question arises: What is the cause of the obvious, and sometimes irresistible, craving of the individual for art, and what is the power of the 'magical' effect of artistic phenomena on the perception of man of his world? In search of an answer, let us first turn to the essential characteristics of the very concept of personality, which has a multitude of meanings both in the psychological and sociological aspects. By the individual is meant, first of all, the social type of the individual, embodying the most significant features of the epoch, the nation and the ethnic group, among other characteristics.

Responding to any social transformations, the personality in its development passes through several regular stages, orientated primarily towards the development of the emotional sphere of intellect, memory, etc. under the influence of which one or another peg of outlook is developed as an organic fusion of knowledge, value priorities and evaluation categories. We are talking about a personally colored experience of the cognizable objects of the material 
world that activates other mechanisms aimed at sensory perception and comprehension of the vital aspirations of artistic phenomena and facts.

Communication with works of art fills the individual's consciousness with spiritually creative energy, allowing adaptation of one's self to the living, informal conditions of interpersonal interaction involving the most effective means of musical expression informing on the past, present and future history and culture of society. By accumulating various psychological states, music captures collective "knowledge of the world" focused on artistic ideas that naturally cannot but contribute to overall the comprehension of value meanings in the infinite whirl of being. It is on this cultural background that a certain set of individual abilities unfolds, among which one can also find the amazing propensity of the human psyche for empathy, revealed through deep involvement in the figurative structure of music.

The axiological view of music allows not only understanding of a wide historical perspective through a vast panorama of styles and genres, where the law of "the reciprocity of the past and the future" operates, but also understanding of causal connections in all phenomena of art life, predicting the spiral of personal upbringing, and contributing to the perception of the spiritual content of being in the world of musical sounds, where in its own way, the triad of the universal values of Istana-good-beauty known since the 17th century is refracted.

\section{DISCUSSION}

Musical art as an integral part of the culture of any people and is a powerful means of entering the spiritual essence that created it to understand not only differences in language, but also those that are figurative, genre-based and stylistic. But how to reveal the high sense of music to listeners, as well as the spiritual experience of humanity conveyed in it? In the transitional period experienced by our contemporaries, when the old and the new come into contact and overcome enormous contradictions in order to achieve a new historical reality and a new sound space, former meanings and values are transformed, developing a new art through which channels of artistic and aesthetic communication function between the past, present and future. In this process, perceiving is helped by the feeling that exists in the person himself. The transforming power of love, for instance, imprinted in the content of music, "passes through our heart, ignites it to the highest, [and is] truly worthy of a person's life", and brings about the realization of important principles underlying the "sound-and-music form of music" such as joy, spiritual activity, worldview and enlightenment of the soul. In other words, musical art, permeating all spheres of human life activity, becomes a powerful spiritual core, upon which the life of the individual is staked. As a result, it fulfils many social functions, among which are socially transforming, sensitive, artistic-conceptual (suggestive), anticipatory, communicative, aesthetic, emotionally empathetic, pragmatic or vitally practical, outlook-forming, ethical and cathartic [6].

Let us emphasize: At the moment of catharsis, which is a state of inner spiritual harmony, when the compassion of the individual becomes aware of the vital problem, the individual is spiritually uplifted. In this process, musical art influences awareness, enlightenment, readiness for good deeds towards oneself, the world, nature and other people, as described by many such as Bach, Mozart, Beethoven, Tchaikovsky, Rachmaninov, Scriabin, M. Tulebaev and G. Zhubanov. Sometimes it is enough to listen only once to the enchanting sounds of music to get to the music, radically changing its original prejudice to the same symphony, which, according to the apt expression of D. Shostakovich, "among other musical genres stands as the first among equals. It is saturated with the deepest content and is the mistress of the musical realm. None of the great people passed by the infinite, inexhaustible wealth of feelings and ideas contained in it, "past the high pleasure that a person gives her knowledge and understanding"

Musical art carries in itself ideas, thoughts and experiences transmitted by means of artistic expressiveness. For millennia, in the course of our evolution, society has moved into spiritual and moral maturation through sensory turmoil, the deepest emotional states. Music is always a real sensualemotional experience (Losev A.F) that harmonizes the individual's relationship with the world. When the individual seeks harmony in developing natural talents and is additionally strong willed, musical education becomes a cultural and historical process. Music lives not only in sound, but in something immeasurably greater, since it enables the person to enter into vital contact with surrounding reality, allowing him to experience and describe it. Here we see a significant condition: any judgment about music is achieved by musical experience: to experience music and to sympathize with it. 
Many researchers have concluded on the artistic value of the melodic principle in music, agreeing that its specific character is manifested in vivid intonations that testify to national, style and genre features and unique color, rhythm, accompaniment etc. In particular, Sochor A.N. noted that a cultural person should not only knows the mind, but should also adequately understand and evaluate music of various genres. Communication with musical art infuses the individual with creative energy, allowing him to adapt to the living, informal conditions of interpersonal interaction. The personal understanding of the values of music not only adds to one's interest, but also becomes the most important effective stimulus for understanding the innermost secrets of the human soul. "Looking at them as a kind of mirror in the characters of works, comparing ourselves with them, we come to a deeper understanding of their actions and thoughts, attitudes towards people, the environment," was mentioned in the research. Here, the main motive is the "aesthetically directed personality-semantic attitude to the art of music and through it to life" [7].

In music, as in the art of sound expression, images created by expressive means are always colored by certain mental states. Regardless of their psychological mood, whether light, joyful, upbeat, or, conversely, gloomy, mournful and detached, they are able to truly captivate even the seemingly unprepared listener, immersing him in an endless stream of internal sensations and experiences. Based on this, it is not an exaggeration to say that every real musical work reflects the creative, spiritually-transforming energy of its creator, whose emotions and impulses serve as an impetus for the musical images created. Music, therefore, allows an insight into its creator's development of emotional reactions, imagination and artistic-aesthetic vision.

Perception of the surrounding world inevitably generates a whole mass of impressions that act as an information field feeding the listener's associativeimaginative thinking with samples of musical art. Being manifested in active form, it gradually develops into a certain quality of personality, possessing a certain listening culture and having a completely expressed spiritual and practical experience for developing stable benchmarks in its assessment of the phenomena of social and musical objective reality.

The outlook of the emerging personality is a particularly complex and multi-component formation, and one of its main properties is interactivity, the desire to embrace and synthesize all aspects of the personality. Among the factors influencing world outlook, music occupies a significant place. World outlook and musical art are closely connected: art in all its forms is the bearer of world outlook content, and worldview, both public and concrete and personal, is formed largely under the influence of art. The worldview expressed by a work of art penetrates into the inner world of the recipient through the filter of the emotions. The work of art leads to formation of a worldview as a psychological process that incorporates the emotions, which gives it its force. Perception of a work of art is inevitably accompanied by the emotional assessment of its content; this is a prerequisite for the transformation of knowledge into beliefs.

The emotional world of the individual is a special space that determines the degree of responsiveness to all phenomena occurring in the surrounding reality. The degree of development of the emotions depends on the individual's ability to feel, participate, empathies and comprehend of life in all its diversity. The emotional tone of music acts as a stimulant for the individual, increasing the need for cognition, providing the ability to reassess values and mobilizing energy resources. In his research, the author mentions, "the hot emotional responsiveness to a musical work not only does not conflict with its intellectual comprehension, but, on the contrary, gets ground, thanks to a clever logical analysis that is able to 'lure' the right range of feelings." The range of feelings towards a work depends on how intensely the individual seeks to understand his impressions of it [8].

Only those who, on the one hand, gain a stable ability to regulate their own expressive experiences, and, on the other, learn to influence their sensual reactions can reach a high level of artistic cultural value. By the degree to which feelings are mastered, one can judge the degree of the individual's artistic maturity and his level of emotional development achieved because, as we know, the power of emotions is so great that they easily influence the individual and those with whom he comes into contact.

The outstanding composer and scholar-researcher, Kabalevsky D. B., devoted his life and creativity to serving universal ideals, the ideological credo of which is the spiritual and moral upbringing of the individual. It is in music that the humanity of art finds itself with the 
greatest force because it is based on the human voice singing and speaking the rhythm of human movement. Dmitry Borisovich stressed that there is no more important, more relevant and meaningful topic than the person in art, since it is created by a person, is created about a person and is created for a person. The great musician was convinced that the knowledge of music and the ability to listen to and to hear it, understand it, feel its connection with other arts and, above all, of course, with life " are necessary for every person. Everyone who understands that "Music is not just art! Music teaches people to understand each other, educates them in humanism, helps mankind to protect the world" [9].

The 20th century, as we know, made serious adjustments to the resources of the creative and transformative principle in man. The desire for constant self-improvement allowed individuals to become full bearers of their worldview. From this point of view, it is musical art that is the area in which the experience of a liberated consciousness, imbued with true interest, deeply motivated by the relation of the individual to phenomena and facts of objective reality, is reflected. Accordingly, the mechanisms of the formation and functioning of the personality in the complex and surprising world of artistic phenomena, including those in the field of musical art, which are the object of special research, force us to take a more thorough look at the very formulation of the indicated problem and to examine it from the point of view of cultural, psychological, sociological and other approaches [10].

In summary, we quote Georgy Sviridov's remarkable statement about the importance of music in the education of the individual: "I want with all my might to recall the ethically exalting function of musical art, that music is intended for the spiritual improvement of man. And this is her main mission." There are many ways to associate with the beautiful, imaginative image of the surrounding world, reflected in one way or another, but none of them does without "passing through oneself," all that causes a special sense of belonging, an inner experience of ideas translated into the content of the work [11].

\section{CONCLUSION}

One starting point in research into music education could be praxial music education philosophy, which represents autonomic music in a liberal way for the best results. Here, the point of view could be found from orientation research, general music orientation or specific music orientation. We also need more information on the significance and meaning of music.

Another point of view might be found in exploring different stages of music appreciation from pursuing it as hobby to profession. The aim of research should explore the extent and strength of cultural enculturation, musical taste, musical worldview and musical self-concept. The musical surroundings of society today are important targets for research because they should form the bases for building music education goals for the future. There is ample information available on the history of music education today. From this, we could and should find our mistakes and misjudgments and learn from them. Many researchers have described the teaching of music education up to the 1980s. The attitudes of teachers towards different music styles and pupils with a musical hobby have been researched and the results show many factors affect in everyday school work.

Questions of musical self-conception should also be taken into account in connection with different musical development stages before the beginning of school and they should be researched. Music education should be planned starting with the results from new research. After the research has revealed what occurs in the implicit enculturation processes before school age, we can begin to explore the directions of the development of music education. Overall, research should explore the possibilities to values; musical self-conception, musical worldview and musical taste development more effectively for the development of music education as a whole [12].

\section{REFERENCES}

[1] Regelski TA. Music subject in Estonian basic education: the reflections of the national curriculum in music teachers pedagogical thinking. Art and emotions, Moscow: Music, 2002.

[2] Juvonen A. Music Education Facing New Challenges, 2005.

[3] Kasanen, Lukka, Design management as a strategic instrument, 2002.

[4] Ananieva BG. Humanity is the main centre of scientific development of modern science, 2007.

[5] Bakhtin MM. muic in education, 2005.

[6] Medushevsky VV. the teory of music communication, 2007.

[7] Anisimov PV. Formation of motivation of educational musical activity for schoolchildren as a teacher training problem.: diss ... candidate of pedagogical sciences 1987 .

[8] Barenboim LA. The way to music making: Studies. - L.: Soviet composer 1979.

[9] Kabalevsky DB.. Creative meetings, essays, letters. [text] D.B. Kabalevsky: comp. and obs. red. V.I. Viktorov. Moscow: Soviet composer 1974. 
[10] Alperson PA. What should one expect from a philosophy of music education? Journal of Aesthetic Education 1991; 25(3): 215-242. Anttila, M. (2000).
[11] Sviridov GN. Music culture of society - Questions of sociology and aesthetics of music 1980.

[12] Rappoport SKh. (1972). Art and emotions. Moscow: Music, 2004.

DOI: https://doi.org/10.6000/2292-2598.2018.06.03.10

(C) 2018 Ritta et al.; Licensee Lifescience Global.

This is an open access article licensed under the terms of the Creative Commons Attribution Non-Commercial License (http://creativecommons.org/licenses/by-nc/3.0/) which permits unrestricted, non-commercial use, distribution and reproduction in any medium, provided the work is properly cited. 